\title{
Evaluasi Tingkat Kepuasan Pasien Terhadap Pelayanan Kefarmasian Di Rumah Sakit Sekarwangi Cibadak Kabupaten Sukabumi.
}

\author{
Diki Muhammad, Almasyhuri, Lusi Agus Setiani \\ Program Studi Farmasi FMIPA, Universitas Pakuan, Bogor, Indonesia \\ Email korespondensi penulis: lusi.setiani@unpak.ac.id
}

\begin{abstract}
ABSTRAK
Kepuasan pasien merupakan penilaian dari seseorang antara kinerja pelayanan yang dirasakan dan diharapkan. Apabila kinerja di bawah harapan maka pasien akan kecewa dan tidak puas, sebaliknya bila kinerja sesuai yang diharapkan pasien, maka pasien akan merasa puas. Pihak rumah sakit harus berhati-hati dalam memberikan pelayanan kesehatan, karena jika pasien sering merasa tidak puas terhadap pelayanan yang diberikan maka akan berdampak hilangnya pelanggan/pasien, serta tingkat kepuasan pasien sangat tergantung pada mutu pelayanan yang diberikan. Rancangan penelitian ini merupakan penelitian Observasional analitik (Non-Exsperimental) menggunakan pendekatan metode cross sectional. tehnik yang digunakan dalam pengambilan sampel adalah accidental sampling dengan jumlah responden 126 orang. dengan cara mewawancarai menggunakan kuisioner yang berisi berupa 15 pertanyaan yang sudah divalidasi. Kepuasan pelayanan kefarmasian diukur dengan mengunakan skala likert. Hasil penelitian tingkat kepuasan pasien pada dimensi tangible diperoleh skor $73,1 \%$, realibility $71,3 \%$, responsiveness $75,1 \%$, assurance $72,3 \%$, dan emphaty $80,3 \%$. Secara keseluruhan didapatkan persentase skor rata-rata $74,4 \%$ maka dikategorikan pasien merasa puas terhadap pelayanan kefarmasian di RSUD Sekarwangi. Pada karakteristik pasien: umur, pekerjaan, kategori pasien (BPJS/Non-BPJS), dan pendidikan terakhir didapat nilai p-value $<0.05$ maka hal itu menunjukan adanya hubungan dengan tingkat kepuasan pasien, sedangkan pada karakteristik pasien jenis kelamin tidak terdapat hubungan dengan tingkat kepuasan pasien, karena nilai p-value $>0.05$.
\end{abstract}

Kata Kunci: Tingkat kepuasan pasien, pelayanan kefarmasian, karakteristik pasien, skala likert, RSUD sekarwangi.

\section{PENDAHULUAN}

Penelitian kepuasan pada setiap rumah sakit sangat dibutuhkan untuk memperoleh informasi tentang kepuasan yang dirasakan oleh pasien. Sehingga rumah sakit menggunakan hasil penelitian untuk lebih memahami kebutuhan dan keinginan pasien serta dapat memberikan pelayanan yang lebih memuaskan (Rahmani, 2009).RSUD Sekarwangi termasuk salah satu rumah sakit rujukan utama 
di daerah Cibadak, yang telah berdiri lama, dan menyandang predikat paripurna pada tahun 2012, dan memiliki fasilitas yang lengkap.Dengan adanya penelitian ini diharapkan apabila terdapat ketidakpuasan pasien dapat membantu rumah sakit untuk memperbaiki kualitas pelayanan kefarmasiannya, namun jika sudah didapatkan kepuasan diharapkan dapat membantu meningkatkan pelayanan kefarmasiannya baik saat ini ataupun dimasa mendatang, sehingga rumah sakit ini sangat dipercaya dan menjadi favorit masyarakat.

Penelitian ini bertujuan untuk mengevaluasi tingkat kepuasan pasien terhadap pelayanan kefarmasian meliputi lima dimensi kualitas mutu pelayanan yaitu tangible, reliability, responsiveness, assurance, emphaty, dan mengetahui hubungan antara karakteristik responden (umur, jenis kelamin, pendidikan terakhir, pekerjaan, kategori pasien) terhadap tingkat kepuasan pasien.

\section{METODE PENELITIAN}

\section{Rancangan Penelitian}

Rancangan penelitian ini termasuk kedalam desain penelitian Observasional analitik (Non-Exsperimental) dengan menggunakan pendekatan metode cross sectional. Analitik merupakan penelitian yang menekankan adanya hubungan antara satu variabel dengan variabel yang lainnya, pada penelitian analitik ini digunakan untuk mencari perbedaan dua variabel. Sedangkan cross sectional adalah penelitian yang mempelajari dinamika kolerasi antara faktor-faktor risiko dengan efek, dengan cara pendekatan, observasi atau pengumpulan data sekaligus pada waktu yang sama (Notoatmodjo, 2010). Pada penelitian ini variabel bebas dan variabel terikat dikumpulkan dan diukur dalam waktu yang bersamaan.

\section{Populasi dan Sampel}

Populasi dalam penelitian ini adalah pasien rawat jalan yang mendapatkan pelayanan kefarmasian di RSUD Sekarwangi Cibadak Kabupaten Sukabumi pada tahun 2019 yaitu sebesar 65496. Sampel pada penelitian ini adalah pasien rawat jalan dipelayanan kefarmasian RSUD Sekarwangi.

\section{Teknik Pengambilan Sampel}

Pengambilan sampel pada penelitian ini berdasarkan teknik accidental sampling. Teknik ini didasarkan pada pengambilan sampel yang dilakukan dengan mengambil sampel yang kebetulan ada pada saat sedang melakukan penelitian (Sani, 2016). Pengambilan jumlah responden dalam penelitian ini yaitu minimal 81 orang menggunakan rumus lemeshow dibawah ini.

$\mathrm{n}=\frac{1,96^{2} \times 0,70 \times 0,30}{0,01}=81$ responden

\section{Tempat Penelitian dan Waktu Penelitian}


Pelaksanaan penelitian ini dilakukan di pelayanan kefarmasian rawat jalan di RSUD Sekarwangi Cibadak. Waktu yang digunakan dalam penelitian ini pada Februari-Maret 2020.

\section{Instrumen Penelitian}

Instrumen penelitian yang digunakan untuk memperoleh data yang dibutuhkan, yaitu lembar kuesioner yang terdiri dari 15 pernyataan. Variabel kepuasan pelayanan kefarmasian diukur dengan alat ukur berupa kuesioner dengan skala pengukuran mengunakan skala likert. Dalam skala likert.

\section{Pengumpulan Data}

Jenis pengumpulan data (Notoatmodjo, 2010):

\section{(a). Data Primer}

Data primer diperoleh melalui kuesioner. Pada saat pengumpulan data peneliti menjelaskan waktu, tujuan, manfaat dan prosedur pelaksanaan kepada calon responden dan yang bersedia berpartisipasi.

(b). Data Sekunder

Data sekunder diperoleh dari berbagai sumber seperti: artikel, buku, ataupun jurnal berkaitan erat dengan kepuasan pasien dengan memanfaatkan teknologi internet untuk mengambil beberapa data yang sesuai dengan tujuan penelitian.

\section{Teknik Analisa Data}

(a). Analisa Univariat

Untuk mendapatkan gambaran umum tentang, deskripsi tiap variable makadilakukan pengumpulan data, selanjutnya data diolah dengan menggunakan uji metode statistik uji univariat pada perangkat computer, agar diperoleh distribusi frekuensinya dengan menggunakan tehnik skala likert.

(b). Analisa Bivariat

Analisis ini untuk mengetahui hubungan antar dua variabel. Analisa bivariat pada penelitian ini membandingkan hubungan antara tingkat kepuasan pasien rawat jalan terhadap karakteristik responden yang sedang berobat ke pelayanan kefarrmasian di Rumah Sakit Sekarwangi dengan menggunakan uji chi square.

\section{Etika Penelitian}

Penelitian ini dilaksanakan berdasarkan persetujuan etik dengan nomor 132/UN6.KEP/EC/2020 yang diterbitkan oleh Universitas Padjadjaran Bandung, pada tanggal 29 Januari 2020.

HASIL DAN PEMBAHASAN 


\section{Karakteristik Responden}

Penelitian ini dilakukan di RSUD Sekarwangi Cibadak pada bulan febuari - maret 2020. Hasil validasi kuesioner kepada 30 orang responden dengan persentase kesalahan 10\% (0,01\%), nilai R-tabel 0,4093, diuji dengan program komputer yaitu SPSS, menghasilkan nilai R-hitung lebih besar dari R-tabel, maka kuisioner dinyatakan valid. Karakteristik responden meliputi jenis kelamin, pendidikan terakhir, pekerjaan, kategri pasien dan umur.

Tabel 1. Frekuensi Karakteristik Pasien di Rumah Sakit Sekarwangi Cibadak.

\begin{tabular}{llcc}
\hline \multirow{2}{*}{ KARAKTERISTIK } & \multicolumn{2}{c}{ RESPONDEN } \\
\cline { 2 - 3 } Jenis kelamin & a. laki-laki & 64 & \% \\
& b. Perempuan & 62 & 50.8 \\
& a. Tidak tamat SD & 4 & 49.2 \\
Pendidikan & b. SD & 27 & 3.2 \\
Terakhir & c. SMP/MTs & 28 & 21.4 \\
& d. & 44 & 22.2 \\
& SMA/SMKsederajat & 23 & 34.9 \\
& e. Perguran Tinggi & 44 & 18.3 \\
& a. Ibu Rumah Tangga & 32 & 34.9 \\
Pekerjaan & b. Buruh & 14 & 25.4 \\
& c. Wirausaha & 15 & 11.1 \\
& d. Pegawai Swasta & 16 & 11.9 \\
& e. Pegawai Negeri & 5 & 12.7 \\
& f. Belum bekerja & 109 & 4.0 \\
Kategori Pasien & a. BPJS & 17 & 86.5 \\
& b. Non-BPJS & & 13.5 \\
Umur & a. 25-30 tahun & 19 & 15.1 \\
& b. 31-40 tahun & 33 & 26.2 \\
& c. 41-50 tahun & 36 & 28.6 \\
& d. 51-60 tahun & 38 & 30.2 \\
\hline
\end{tabular}

Pada Tabel 1, dapat dilihat bahwa kategori pertama yaitu jenis kelamin, laki laki lebih banyak dibandingkan dengan perempuan, dalam penelitian ini adalah $50,8 \%$ laki-laki dan 49,2\% perempuan, Kedua yaitu kategori pendidikan terakhir terbanyak adalah tingkat SMA/SMK/Sederajat yaitu sebanyak 34,9\%, dan jumlah yang paling sedikit adalah tidak tamat Sekolah Dasar (SD) yaitu sebanyak 3,2\%, Ketiga yaitu kategori pekerjaan terbanyak adalah ibu rumah tangga yaitu sebanyak $34,9 \%$, dan jumlah yang paling sedikit adalah belum bekerja yaitu sebanyak $4,0 \%$. Keempat yaitu kategori pasien, hasil menunjukan bahwa kategori pasien BPJS sebanyak $86,5 \%$, dan non BPJS sebanyak 13,5\%. Dari data berikut dapat dilihat 
bahwa pasien dengan kategori BPJS lebih besar dibandingkan dengan pasien non BPJS.Kelima yaitu kategori umur, dapat dilihat bahwa pasien yang bersedia menjadi responden terbanyak adalah usia 51-60 tahun sebanyak $30,2 \%$, dan yang paling sedikit adalah pasien pada rentan usia 20-35 tahun yaitu sebanyak 15,1\%.

\section{Hubungan jenis kelamin dengan tingkat kepuasan}

Data diperoleh bahwa tidak terdapat hubungan antara jenis kelamin dengan tingkat kepuasan, karena nilai signifikan yang diperoleh $p>0,05$ yaitu 0,682 . Hal ini sejalan dengan penelitian lain tentang hubungan karakteristik dengan kepuasan pasien rawat jalan di Puskesmas Sindangkerta, Bandung, yang menyatakan tidak terdapat hubungan antara tingkat kepuasan dengan perbedaan jenis kelamin (Asep D, A dan Ramdan M, 2009). Namun hasil ini berbeda dengan pendapat lumenta dalam (budiman dkk, 2010) bahwa jenis kelamin mempengaruhi tingkat kepuasan karena laki-laki memiliki tutuntan besar cenderung merasa tidak puas dibandingkan dengan perempuan.

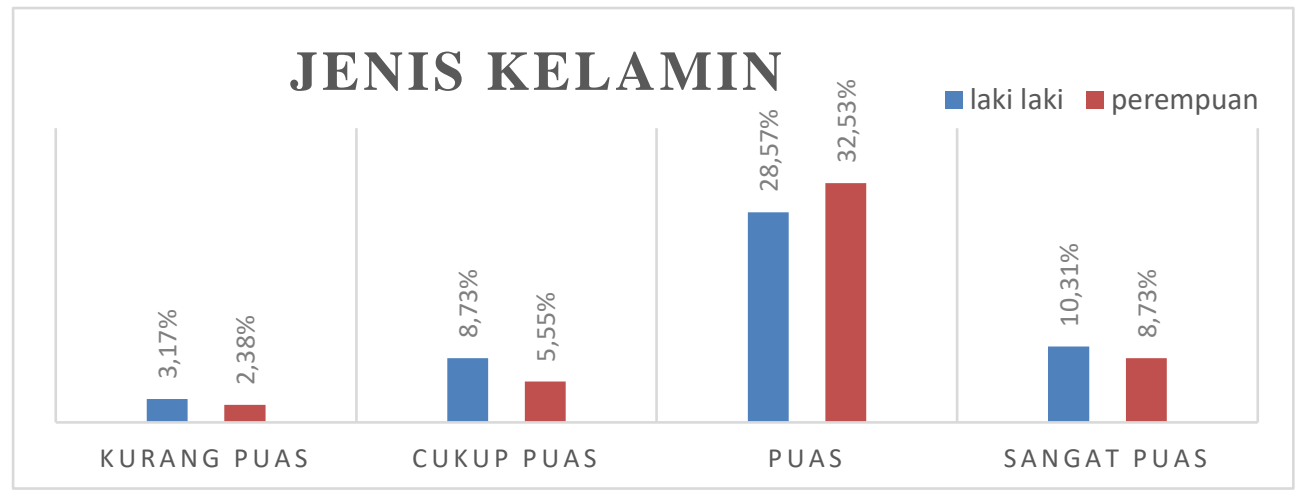

Gambar 1. Diagram batang sebaran tingkat kepuasan kategori jenis kelamin

\section{Hubungan pendidikan dengan tingkat kepuasan pasien}

Data diperoleh bahwa terdapat hubungan antara tingkat kepuasan pasien dengan pendidikan terakhir pasien, karena nilai signifikan yang diperoleh $\mathrm{p}<0,05$ yaitu 0,000. Hasil ini sejalan dengan penelitian di Rumah Bersalin Citra Lestari Pabuaran, Bogor yaitu terdapat hubungan antara pendidikan dengan tingkat kepuasan pasien terhadap pelayanan kefarmasian (Hayuningsih S, 2018). Hal ini menunjukan bahwa semakin tinggi tingkat pendidikan responden, maka akan semakin memiliki informasi luas, sehingga orang yang berpendidikan tinggi akan berpengetahuan lebih baik dibandingkan dengan berpendidikan rendah (Nursalam, 2001).

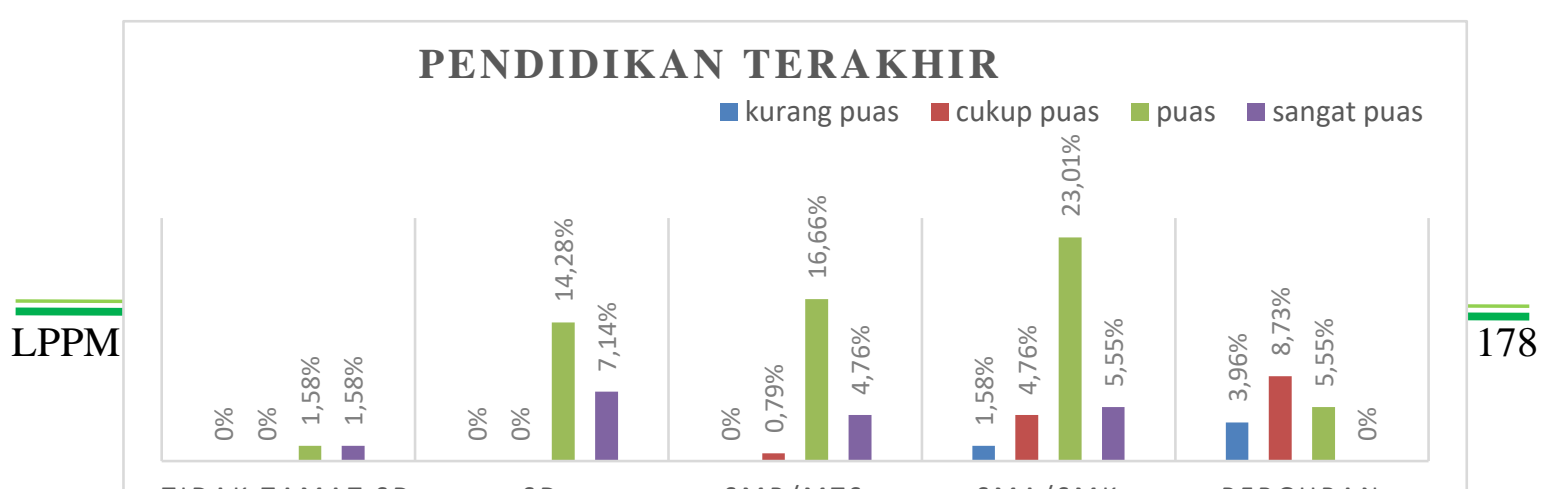


Gambar 2. Diagram batang sebaran tingkat kepuasan kategori pendidikan terakhir.

\section{Hubungan pekerjaan dengan tingkat kepuasan pasien}

Terdapat hubungan antara pekerjaan dengan tingkat kepuasan pasien, dikarenakan nilai signifikan $\mathrm{p}<0,05$ yaitu 0,000. Hasil ini sejalan dengan penelitian di Rumah Bersalin Citra Lestari Pabuaran, Bogor yaitu terdapat hubungan antara pekerjaan dengan tingkat kepuasan pasien terhadap pelayanan kefarmasian (Hayuningsih S, 2018). Seseorang yang memiliki pekerjaan, lebih banyak menuntut dan mengkiritk pelayanan yang didapatkannya dibandingkan dengan yang tidak memiliki pekerjaan (Lumenta PG, dkk 2017).

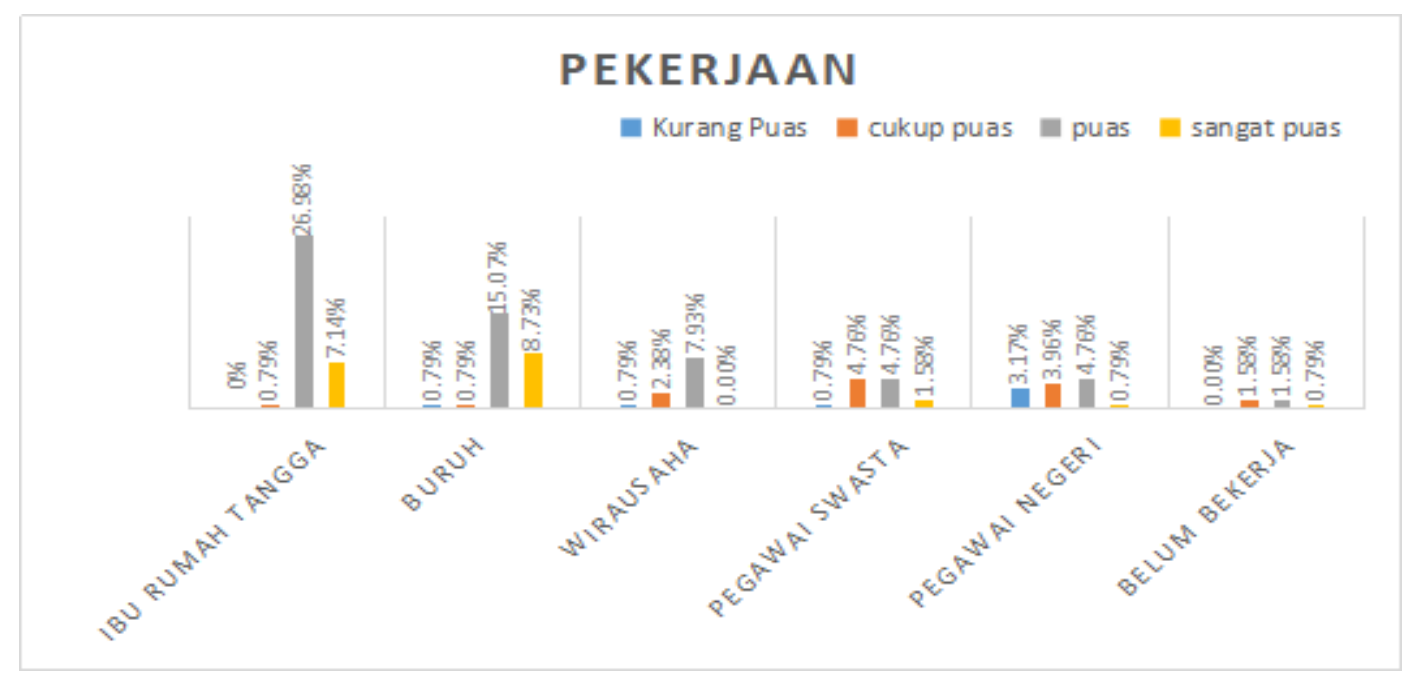

Gambar 3. Diagram batang sebaran tingkat kepuasan kategori Pekerjaan.

\section{Hubungan kategori pasien dengan tingkat kepuasan pasien}

Terdapat hubungan antara jenis pelayanan dengan tingkat kepuasan pasien, dikarenakan nilai signifikan lebih kecil dari 0,05 yaitu 0,005. Hasil ini seusai dengan hasil penelitian lainya di Rumah Sakit Budi Lestari, Bekasi, bahwa pasien BPJS dan Non BPJS Memiliki hubungan dengan tingkat kepuasan pasien (Hidayat G.M, 2017). Menurut Wijono dalam (Asep DA, 2009) terdapat perbedaan tingkat kepuasan dari seseorang yang membayar produk dengan harapan mendapat kulalitas pelayanan yang lebih baik, dibandingkan dengan seseorang yang mendapatkan produk itu secara gratis. 


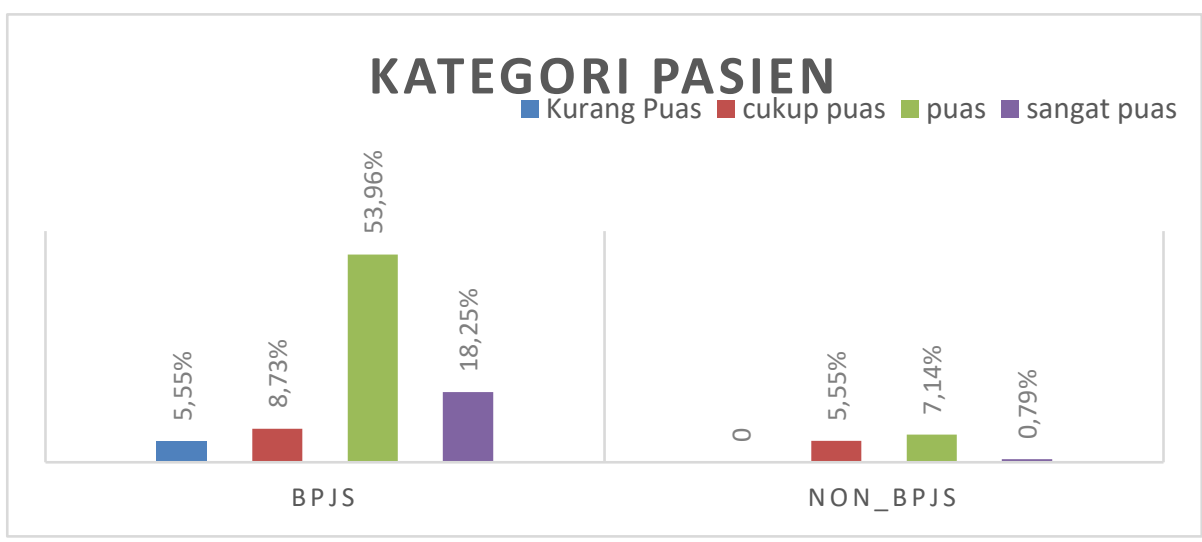

Gambar 4. Diagram batang sebaran tingkat kepuasan kategori pasien.

\section{Hubungan umur dengan tingkat kepuasan pasien}

Terdapat hubungan antara umur dengan tingkat kepuasan pasien, dikarenakan nilai signifikan $\mathrm{p}<$ dari 0,05 yaitu 0,001. Hasil ini sesuai dengan penelitian lain di Puskesmas Sindangkerta Kabupaten, Bandung Barat, bahwa terdapat hubungan antara umur dengan tingkat kepuasan pasien (Asep D, A dan Ramdan M, 2009). Hal ini menunjukkan bahwa umur itu mempengaruhi tingkat kepuasan pasien karena responden berumur produktif cenderung meununtut dan berharap banyak terhadap kemampuan pelayanan kefarmasian dan cenderung mengkritik terhadap pelayanan yang diterimanya (Satrio, 2003).

\section{Evaluasi Tingkat Kepuasan}

Bukti Fisik (Tangible)

Kemampuan perusahaan yang menunjukan eksisteninya baik sarana prasarana fisik yang diberikan oleh pemberi jasa. Fasilitas fisik seperti gedung, gudang, dan lain lain, perlengkapan dan peralatan yang digunakan (teknologi), serta penampilan pegawainya (Tjiptono, 2012).

Tabel 2. Sebaran Tingkat Kepuasan Pasien Berdasarkan Bukti Fisik.

\begin{tabular}{|c|c|c|c|}
\hline $\begin{array}{l}\mathbf{N} \\
\mathbf{O}\end{array}$ & KEPUASAN TERHADAP & $\begin{array}{l}\text { PERSENTASE } \\
(\%)\end{array}$ & $\begin{array}{l}\text { KRITERI } \\
\text { A }\end{array}$ \\
\hline 1 & $\begin{array}{l}\text { kenyamanan fasilitas ruang tunggu di } \\
\text { pelayanan kefarmasian RS. Sekarwangi }\end{array}$ & 74,1 & PUAS \\
\hline 2 & $\begin{array}{l}\text { Kebersihan dilingkungan pelayanan } \\
\text { kefarmasian RS Sekarwangi. }\end{array}$ & 72,8 & PUAS \\
\hline 3 & $\begin{array}{l}\text { penataan ruangan eksterior dan interior di } \\
\text { pelayanan kefarmasian RS Sekarwangi. }\end{array}$ & 72,5 & PUAS \\
\hline & RATA RATA & 73,1 & PUAS \\
\hline
\end{tabular}


Dalam Tabel 2 data diatas dapat disimpulkan bahwa, pada pelayanan dimensi bukti fisik, didapatkan persentase skor rata-rata 73,1\% dihitung secara skala likert dikategorikan bahwa pasien sudah merasa puas terhadap pelayanan bukti fisik di RSUD Sekarwangi. Menurut Kathrin dalam (Wulandari dkk, 2015) penampilan fisik fasilitas kesehatan mempengaruhi pelayanan dapat mempengaruhi lama waktu tunggu dan mendapat pelayanan yang diharapkan, dari kebersihan, kenyamanan, kelengkapan alat merupakan factor penting untuk menjamin keberlangsungan berobat.

\section{Kehandalan (Realibility)}

Pada dimensi ini merupakan kemampuan suatu perusahaan dalam memberikan pelayanan yang dijanjikan dengan akurat, terpercaya kepada pasien (Zahruli, 2006).

Tabel 3 Sebaran Tingkat Kepuasan Pasien Berdasarkan Kehandalan.

\begin{tabular}{llcc}
\hline No & \multicolumn{1}{c}{ KEPUASAN TERHADAP } & $\begin{array}{c}\text { PERSENTASE } \\
(\mathbf{\%})\end{array}$ & KRITERIA \\
\hline 4 & $\begin{array}{l}\text { Kecepatan pelayanan obat di pelayanan } \\
\text { kefarmasian RS Sekarwangi. } \\
\text { pelayanan petugas farmasi di RS }\end{array}$ & 54,4 & $\begin{array}{l}\text { CUKUP } \\
\text { PUAS } \\
\text { PUAS }\end{array}$ \\
$\begin{array}{l}\text { Sekarwangi saat melayani pasien. } \\
\text { keterampilan petugas dalam } \\
\text { memberikan pelayanan informasi obat. } \\
\text { prosedur pelayanan farmasi (mudah, } \\
\text { dan tidak berbelit-belit). }\end{array}$ & $78,76,5$ & PUAS \\
\hline & PATA RATA & $\mathbf{7 1 , 3}$ & PUAS \\
\hline
\end{tabular}

Pada Tabel 3 diatas diketahui, bahwa pasien merasa puas terhadap pelayanan, keterampilan petugas, dan prosedur pelayanan, akan tetapi pada kecepatan pelayanan obat pasien merasa cukup puas, dengan demikian dapat disimpulkan bahwa pada dimensi ini pasien sepenuhnya sudah puas karena didapatkan ratarata persentase skor $71,3 \%$. Dikategorikan dengan skala likert pasien merasa puas terhadap pelyanan kefarmasian pada dimensi kehandalan yang didapatkan di RSUD Sekarwangi. Menurut (Parasuraman, 2001) diperlukan adanya suatu penjelasan secara bijaksana, dalam membina, dan mengarahkan serta membujuk agar dapat menyikapi segala bentuk-bentuk prosedur dan mekanisme kerja yang berlaku dalam suatu organisasi, sehingga mendapat respon baik pada bentuk pelayanan.

\section{Daya tanggap (Responsiveness)}

Suatu kebijakan untuk membantu dan memberikan pelayanan yang cepat dan tepat dengan penyampaian informasi yang jelas. Membiarkan konsumen menunggu 
persepsi yang negatif dalam kualitas pelayanan (Tjiptono, 2012). Dari pengamatan peneliti petugas bersedia dan ramah saat melakukan interaksi dengan pasien, tidak tergesa tegesa dalam melayani pasien,dan saat mengangi tanya jawab kepada pasien penuh dengan senyuman sehingga pasien tidak merasa tertekan saat bertanya. Untuk mengetahui sebaran tingkat kepuasan pasien berdasarkan daya tanggap dapat dilihat Tabel 4.

Tabel 4. Sebaran Tingkat Kepuasan Pasien Berdasarkan Daya Tanggap.

\begin{tabular}{clcc}
\hline NO & \multicolumn{1}{c}{ KEPUASAN TERHADAP } & $\begin{array}{c}\text { PERSENTASE } \\
\mathbf{( \% )}\end{array}$ & KRITERIA \\
\hline 8 & $\begin{array}{l}\text { Petugas farmasi di RS Sekarwangi dalam } \\
\text { menangani tanya jawab para pasien. }\end{array}$ & 74,2 & PUAS \\
9 & $\begin{array}{l}\text { Sikap keramahan petugas farmasi di RS } \\
\text { Sekarwangi dalam melayani para pasien. }\end{array}$ & 79,8 & PUAS \\
10 & $\begin{array}{l}\text { Petugas farmasi di RS. Sekarwangi saat } \\
\text { melayani (tergesa-gesa dalam melayani para } \\
\text { pasien.) }\end{array}$ & 71,4 & PUAS \\
\hline \multicolumn{1}{c}{ RATA RATA } & $75, \mathbf{1}$ & PUAS \\
\hline
\end{tabular}

Pada Tabel 4 diatas dapat diketahui, bahwa pasien sepenuhnya sudah merasa puas terhadap pelayanan yang diberikan RSUD Sekarwangi dalam dimensi ini, didapatkan rata-rata persentase skor 75,1\% dikategorikan dengan menggunakan skala likert yaitu pasien merasa puas denganpelayanan kefarmasian di RSUD Sekarwangi pada dimensi daya tanggap. Menurut (Asmuji, 2013) hubungan antara tingkat kepuasan pasien dengan dimensi daya tanggap adalah hasil stimulus panca indera pasien dari pelayanan yang dirasakan sehingga nantinya menilai mutu pelayanan.

\section{Jaminan (Assurance)}

Meliputi sikap kesopanan, pengetahuan dan keterampilan petugas, dan terjamin ketersedian obat yang lengkap, sehingga menumbuhkan rasa percaya dan keyakinan para pelanggan (Tjiptono, 2012). Dari hasil pengamatan peneliti dilapangan, petugas kefarmasian selalu bersikap ramah, tidak berbicara dengan nada tinggi, selalu bersedia menangani tanya jawab saat pasien hendak bertanya, akan tetapi pada keterjaminan obat itu perlu ditingkatkan lagi dengan memonitoring BPJS agar obat selalu tersedia, Untuk mengetahui sebaran tingkat kepuasan pasien berdasarkan jaminan dapat dilihat pada Tabel 5 dibawah ini.

Tabel 5. Sebaran Tingkat Kepuasan Pasien Berdasarkan Jaminan.

$\begin{array}{lccc}\text { NO KEPUASAN TERHADAP } & \begin{array}{c}\text { PERSENTASE } \\ (\%)\end{array} & \begin{array}{c}\text { KRITERIA } \\ \end{array}\end{array}$




\begin{tabular}{clcc}
\hline 11 & $\begin{array}{l}\text { Sikap kesopanan petugas farmasi di RS } \\
\text { Sekarwangi kepada pasien. }\end{array}$ & 82,6 & $\begin{array}{c}\text { SANGAT } \\
\text { PUAS }\end{array}$ \\
$\begin{array}{l}\text { Pengetahuan dan keterampilan petugas } \\
\text { farmasi dalam bekerja. } \\
\text { Terjaminnya ketersediaan obat yang lengkap } \\
\text { di RS Sekarwangi. }\end{array}$ & 76,3 & 58,1 & $\begin{array}{c}\text { PUAS } \\
\text { CUKUP } \\
\text { PUAS }\end{array}$ \\
\hline RATA RATA & $\mathbf{7 2 , 3}$ & PUAS \\
\hline
\end{tabular}

Pada Tabel 5 dapat ketahui bahwa, sikap kesopanan petugas saat memberi informasi obat, pasien merasa sangat puas terhadap pelayanan yang diberikan, pada keterampilan dan pengetahuan petugas, pasien sudah merasa puas, akan tetapi pada terjaminnya ketersediaan obat pasien merasa cukup puas, karena pasien merasa obat yang diberikan tidak sepenuhnya mereka dapatkan dan mengeluh harus membeli obat di tempat lain, akan tetapi hal itu terjadi dikarenakan pada saat ini BPJS sedang dalam keadaan bermasalah sehingga obat yang didapatkan kurang lengkap, dan pihak RSUD Sekarwangi sudah memberikan pelayanan maksimal terkait hal itu, dengan demikian dapat disimpulkan bahwa dalam dimensi jaminan (Assurance), tingkat kepuasan pasien didapatkan skor ratarata $72,3 \%$ dikategorikan berdasarkan skala likert pasien merasa puas terhadap pelayanan dimensi jaminan yang diberikan RSUD Sekarwangi. Kepastian dari suatu pelayanan dipengaruhi oleh jaminan petugas saat memberikan pelayanan, sehingga responden yang menerima pelayanan merasa puas dan yakin bahwa segala bentuk urusan pelayanan yang dilakukan akan tuntas, selesai pada waktu yang cepat, tepat, mudah, lancar (Parasuraman, 2001).

\section{Perhatian (emphaty)}

Pelayanan akan berjalan baik dan berkualitas apabila semua pihak yang berkepentingan dengan pelayanan terdapat rasa perhatian dalam memberikan pelayanan tanpa melihat status sosial yang berkunjung (Parasuraman, 2001) dalam pengamatan peneliti di rumah sakit sekarwangi, pelayanan kefarmasian dilakukan sama tanpa membedakan status sosial, dari pengambilan obat sesuai dengan nomor antrian, dan memahami kebutuhan pasien seperti saat tanya jawab dengan pasien dilakukan dengan ramah dan sopan. Untuk mengetahui sebaran tingkat kepuasan pasien berdasarkan perhatian dapat dilihat pada Tabel 6 dibawah ini.

Tabel 6 Sebaran Tingkat Kepuasan Pasien Berdasarkan Perhatian.

KEPUASAN TERHADAP $\quad$ PERSENTASE (\%) $\quad$ KRITERIA


14 Pelayanan kefarmasian di RS Sekarwangi, tentang "memberikan pelayanan yang sama tanpa membedakan status sosial".

SANGAT

81,7

PUAS

SANGAT

79

PUAS kebutuhan pasien dan memberikan solusi RATA RATA 80,3 PUAS

Pada data Tabel 6 diatas dapat disimpulkan bahwa pasien sudah merasa sangat puas terhadap dimensi ini, didapatkan rata-rata persentase skor 80,3\% dikategorikan dalam skala likert yaitu sangat puas.

Skala Likert diperuntukan untuk mengukur suatu sikap, persepsi dan pendapat terkait fenomena sosial. Pada setiap pilihan jawaban diberikan skor, selanjutnya responden harus menggambarkan dan mendukung pernyataan yang sesuai (Sugiyono, 2010) kategori puas skala dalam likert dapat dilihat pada Tabel 7 dibawah ini.

Tabel 7 Skala Tehnik Likert.

\begin{tabular}{cc}
\hline KATEGORI & NILAI \\
\hline Sangat memuaskan & $80 \%-100 \%$ \\
Memuaskan $=$ & $60 \%-80,9 \%$ \\
\hline KATEGORI & NILAI \\
\hline Cukup Puas & $40 \%-59,9 \%$ \\
Tidak memuaskan & $20 \%-39,9 \%$ \\
Sangat tidak memuaskan & $0 \%-19,9 \%$ \\
\hline
\end{tabular}

Kepuasan adalah tingkatan perasaan dari seseorang setelah membandingkan kinerja ataupun hasil pelayanan yang dirasakan kemudian dibandingkan dengan apa yang diharapkan seseorang tersebut (Irine, 2009). Secara keseluruhan pada penelitian evaluasi tingkat kepuasan pasien di RSUD Sekarwangi dapat dilihat pada Tabel 8 dibawah ini.

Tabel 8 Hasil Evaluasi Tingkat Kepuasan Pasien.

\begin{tabular}{cccc}
\hline No & Dimensi & Persentase skor (\%) & Keputusan \\
\hline 1 & Bukti Fisik (Tangible) & 73,1 & Puas \\
2 & Kehandalan (Reliability) & 71,3 & Puas \\
3 & Daya Tanggap (Responsiveness) & 75,1 & Puas \\
& & & \\
4 & Jaminan (Assurance) & 72,3 & Puas \\
5 & Perhatian (Emphaty) & 80,3 & Sangat puas \\
\hline & Rata rata & $\mathbf{7 4 , 4}$ & Puas \\
\hline
\end{tabular}


Berdasarkan Tabel 10 dapat disimpulkan bahwa Tingkat kepuasan pasien dengan jumlah sampel 126 responden, pada dimensi bukti fisik (tangible) diperoleh skor $73,1 \%$, kehandalan (realibility) sebanyak 71,3\%, daya tanggap (responsiveness) sebanyak 75,1\%, jaminan (assurance) sebanyak 72,3\%, dan perhatian (emphaty) $80,3 \%$.

Diperoleh evaluasi tingkat kepuasan pasien terhadap pelayanan kefarmasian di RSUD Sekarwangi secara keselurahan dengan rata-rata persentase skor keseluruhan 74,4\% dikategorikan dalam skala likert bahwa pasien merasa puas terhadap pelayanan kefarmasian di RSUD Sekarwangi.

\section{KESIMPULAN DAN SARAN}

Tingkat kepuasan pasien pada dimensi bukti fisik tangible diperoleh skor 73,1\%, kehandalan realibility $71,3 \%$, daya tanggap responsiveness $75,1 \%$, jaminan assurance $72,3 \%$, dan perhatian emphaty $80,3 \%$. Persentase keseluruhan tingkat kepuasan pasien adalah 74,4\%. Hal ini dapat disimpulkan bahwa Pasien puas terhadap pelayanan kefarmasian di RSUD Sekarwangi, dan Terdapat hubungan antara karakteristik umur, pendidikan terakhir, pekerjaan, kategori pasien, dikarenakan nilai $\mathrm{p}$-value $<0,05$ sedangkan untuk jenis kelamin tidak terdapat hubungan dikarenakan nilai p-value $>0,05$.

Selanjutnya, pihak RSUD Sekarwangi dapat lebih meningkatkan kualitas pelayanannya terutama kecepatan pelayanan obat dan ketersediaan obat sarannya untuk kecepatan pelayanan obat dengan menambah jumlah tenaga kefarmasian atau menyediakan media pengambilan obat secara online agar meningkatkan kecepatan pelayanan obatnya, sedangkan untuk ketersediaan obat perlu adanya monitoring BPJS sedini mungkin agar obat obatan tetap tersedia.

\section{UCAPAN TERIMAKASIH}

Penulis mengucapkan banyak terimakasih kepada pihak RSUD Sekarwangi Cibadak yang telah bersedia menjadi tempat penelitian, selanjutnya kepada dosen pembimbing di Universitas Pakuan yang telah membantu membimbing sehingga terwujudnya skripsi ini.

\section{DAFTAR PUSTAKA}

Asmuji, 2013 Manajemen keperawatan, cetakan ke II Edisi duabelas, r-Ruzz Media .Hal 188. Yogyakarta,

Bogadenta A. 2012. Manajemen Pengelolaan Apotek. D-Medika: Yogyakarta.

Daulay, M.A. 2015. Tingkat kepuasan pasien rawat jalan peserta BPJS kesehatan terhadap pelayanan kefarmasian di dua puskesmas di Kota Medan. Skripsi, Fakultas Farmasi, Universitas Sumatera Utara. 
Depkes RI Buku Saku FAQ (Frequently Asked Questions) BPJS. Kementerian Kesehatan RI: Jakarta.

Kamil Hajjul, 2010. Tingkat Kepuasan Pasien Terhadap Mutu Pelayanan Kesehatan Di RSUDZA Banda Aceh, Jurnal Ilmiah, Keilmuan Keperawatan Dasar Dasar Keperawatan PSIK-FK Universitas Syiah Kuala, Banda Aceh, ISSN: 2087-2879. Larasaty F. P Luh, 2015. Pengaruh Pelayanan Kefarmasian Residensial terhadap Ketaatan dan Luaran Klinis Pasien Hipertensi, jurnal ilmiah, Universitas Udayana Jimbaran, Bali, Indonesia ISSN: 2252-6218.

Librianty Nany, 2017, Faktor-Faktor Yang Mempengaruhi Kepuasan Pasien Terhadap Pelayanan Kesehatan Rawat Jalan Puskesmas Bandar Petalangan Pelalawan, Jurnal Ilmiah Universitas Phalawan Tuanku Tambusai, ISSN 26231573.

Muhibbin Syah, 2010 Psikologi Pendidikan Dengan Pendekatan Baru. Bandung: PT Remaja Rosdakarya.

Noviana P, 2017 Analisis Tingkat Kepuasan Pasien Rawat Jalan Terhadap Pelayanan Instalasi Farmasi di RSUD Pare Menggunakan SERVQUAL,Jurnal wiyata Vol 4 No 2. ISSN:2442-6555

Nurhaeni F, Kristoyono E dan Mardikanto O ,2016 Analisis kepuasan pelanggan dengan metode SERVQUAL di Rumah Sakit Condong Catur Yogyakart, jurnal ilmiah, POLTEKES BSI Yogyakarta Volume 4 no 1. ISSN:2337-6007.

Novaryatiin S, Syahrida Dian Ardhany, \& Siti Aliyah. 2018 Tingkat Kepuasan Pasien Terhadap Pelayanan Kefarmasian di RSUD Dr Murjani Sampit Jurnal ilmiah Fakultas Farmasi Univeristas Muhammadiyah Palangkaraya. Vol 1 no 1. e-ISSN: 2621-4814.

Saman, 2020 Kabupaten Sukabumi Dalam angka (Sukabumi Regency in Figures 2020). Badan Pusat Statistik Kabupaten Sukabumi.

Sani, R A. 2016. Inovasi pembelajaran. Jakarta: Bumi Aksara.

Supardi. 2014. Penelitian Tindakan Kelas. Jakarta. Penerbit Bumi Aksara. BNSP.

Supardi U.S 2013 Aplikasi Statistika Dalam Penelitian : Konsep Statistika Yang Lebih Komperhensif .Change Publication ; Jakarta.

Supranto, J. 2011. Pengukuran Tingkat Kepuasan Pelanggan Untuk Menaikkan Pangsa Pasar, Cetakan keempat, Penerbit PT Rineka Cipta, Jakarta.

Tjiptono, 2012 Service Management Mewujudkan Layanan Pria, Yogyakarta. 